\title{
Online or Face-to-Face Microbiology Laboratory Sessions? First Year Higher Education Student Perspectives and Preferences
}

\author{
Susan Salter ${ }^{1 *}$, Christine Gardner ${ }^{2}$ \\ ${ }^{1}$ Faculty of Health, University of Tasmania, Launceston, Australia \\ ${ }^{2}$ Faculty of Education, University of Tasmania, Launceston, Australia \\ Email: :Susan.Salter@utas.edu.au
}

Received 20 June 2016; accepted 21 August 2016; published 24 August 2016

Copyright (C) 2016 by authors and Scientific Research Publishing Inc.

This work is licensed under the Creative Commons Attribution International License (CC BY).

http://creativecommons.org/licenses/by/4.0/

(c) (i) Open Access

\section{Abstract}

Reducing the number of face-to-face laboratory sessions and supplementing with virtual/online alternatives are critical to managing the combined pressures of increasing first-year student numbers and decreasing university budgets. Most of the research studies about online practicals are hypothesis generating rather than hypothesis testing thus only providing initial support and direction for the generation of pedagogically sound online laboratory teaching. This pilot study investigated the effectiveness of using a combination of online and face-to-face practical sessions to enable students in a Microbiology unit, offered to students completing several health science courses, to connect discipline-specific theory and practical application. Quantitative and qualitative data were gathered using a paper-based questionnaire from 72 first-year students. Results showed that 65 percent of students preferred a combination of face-to-face and online sessions. Furthermore, determinants for engagement with online sessions varied with student gender.

\section{Keywords}

Biomedical and Health Sciences, Higher Education, Microbiology, Online and Face-to-Face Practicals

\section{Introduction}

Decreasing university budgets and staff, and increasing student cohorts, have resulted in laboratory teaching "Corresponding author.

How to cite this paper: Salter, S., \& Gardner, C. (2016). Online or Face-to-Face Microbiology Laboratory Sessions? First Year Higher Education Student Perspectives and Preferences. Creative Education, 7, 1869-1880. 
spaces being at a premium, or even insufficient, particularly for first-year cohorts (Papo, 2001). The practice of reducing the number of face-to-face laboratory sessions and supplementing these with virtual/online alternatives is a strategy being trialled to cope with increasing demands on learning spaces and resources (Baker \& Verran, 2004; Blewett \& Kisamore, 2009). In addition to the face-to-face laboratory sessions, the use of virtual (online) practicals is particularly appropriate for first-year microbiology students who are required to develop generic skills based on foundation microbiology curricula as opposed to subsequent years where more specialised laboratory techniques based on advanced theory are better handled in wet (face-to-face) laboratories. Online practicals have been trialled in a wide variety of specific science/biological disciplines including histology, microbiology, pharmacology and dentistry (Evans, Gibbons, Sha, \& Griffin, 2004; Gilman, 2006; Sancho et al., 2006; Wahlgren, Edelbring, Fors, Hindbeck, \& Stahle, 2006). These practicals have covered specific areas such as slide staining and interpretation (histology, microbiology) and occupational health and safety (dentistry). Studies of these trials typically have employed one-dimensional methodologies (Dee, Lehman, Consoer, Leaven, \& Cohen, 2003). Many of these studies are also hypothesis generating rather than hypothesis testing and, as such, provide initial support and direction for the generation of pedagogically sound and student-supported online laboratory teaching (Sunal, Sunal, Odell, \& Sundberg, 2003).

From a generic curriculum perspective, Sunal et al. (2003) in their review of best practices for the development and review of combined online learning and face-to-face instruction, concluded that online instruction was either equivalent to or better than traditional face-to-face teaching methodology, and that online activities allowed the students to progress at their own speed. Finkelstein et al. (2005) used traditional methodology supported by virtual laboratories to provide active learning experiences to engage students in physics education. Johnson and Gedney (2001), in a study of microbiology students using one of the few computer simulation virtual methodologies, suggested that using additional computer based material, including simulations, was an effective tool for deeper understanding of material. Saunders and Klemming (2003), in a survey of undergraduate students in a School of Biosciences unit, reported student comments such as "web-based resources helped fill in the gaps when I switched off in a class" (p. 70).

With respect to gender and online technology, early studies were focused on attitudes to internet technology and computer use (Rajagopal \& Bojin, 2003; Sullivan, 2001). Subsequently, Hargittai and Shafer (2006) investigated users' ability to navigate through online content and found that differences in gender dynamics were more obvious when it related to self-perception of skills and that "women tend to rate their online skills lower than men do" (p. 444). The participants in their study (males and females) came from a wide range of backgrounds and occupations including students, and their findings indicated that level of education was also an important predictor of ability. Similarly, Astleitner and Steinberg (2005) in a literature review on gender differences in web-based learning, suggested that gender differences were insignificant and that online proficiency was more likely to be influenced by individual motivational, cognitive and emotional processes. Cuadrado-Garćia, Ruiz-Molina and Montoro-Pons (2010), investigating the premise that the previous studies had indicated that males and females differ in their interaction with technology, found that there are few differences between the use of, and motivation and satisfaction with, e-learning between males and females. In contrast, Hiltz and Shea (2005) posited that females' preference was for communicating with other students and the lecturer/instructor whilst males preferred accessing information on the Internet. None-the-less, this does not appear to affect their demonstrated learning outcomes.

Our current study, which examined how a cohort of male and female students in a microbiology unit comprising face-to-face and online practical sessions, is looking at whether the above-mentioned concepts also apply to students' experiences. Maldarelli et al. (2009), in a study of first year students enrolled in general biology, reported that purpose-made video support material "showed as strong an effect as performance of the laboratory technique alone" and that 70 per cent of the students surveyed agreed that videos of laboratory experiments "were effective in increasing student knowledge, experience and understanding of laboratory procedures" ( $p$. 56). Papo (2001) supported the co-opting of current and new educational technologies particularly in support of larger cohorts and viewed this mutual learning experience as the "new educational paradigm" (p. 99). In a small study $(\mathrm{n}=38)$ of a virtual biology laboratory, Stuckey-Mickell and Stuckey-Danner (2007) suggested that these technologies provide a great opportunity for further research and development.

This focused on students enrolled in an undergraduate Microbiology and Health unit. This Faculty of Health Science foundation unit is designed to provide a basic understanding of microbiology in relation to infectious disease processes and laboratory skills, and enrolls students from a variety of Faculties and Schools at the Uni- 
versity of Tasmania. The unit is web-dependent and students are familiar with learning objectives and outcomes based around self-motivation and the use of virtual learning resources.

This study investigated:

Student perceptions of using a combination of four online practical sessions followed by two face-to-face laboratory-based sessions to present the theory and practical components in a first-year Microbiology unit;

1) Whether an online practical component can engage students to recognize, recall, connect and apply discipline specific foundation theory to practical content at the first-year level;

2) Whether the online format of delivering practical material, which is designed to incorporate and support independent learning styles, will support and extend student application of discipline specific practical knowledge;

3) These three issues were further examined from a gender perspective.

After the final face-to-face laboratory session, a paper-based questionnaire was employed to gather both quantitative and qualitative data.

\section{Instructional Design of Practicals}

In instructional design, the learner should be the focus of the teaching (Swan, 2001).

This focus should target characteristics of learners such as motivation, satisfaction and perceived usefulness of the learning resource (Cook, 2006; Shibley, Amaral, Shank, \& Shibley, 2011). When the process includes blended learning then learning theories including constructivism, cognitivism and behaviourism should be embedded in the design (Alonso, Lopez, Manrique, \& Viñes, 2005). The outcomes from blending online and face-to-face practicals in this foundation microbiology unit included skills and theory acquisition which students used to research, design and write a major assessment based around the practical laboratory work. The outcomes were based around Bloom's revised Taxonomy (Anderson \& Krathwohl, 2001) and Bigg's SOLO taxonomy (Phillips \& Bond, 2004). Table 1 presents a summary of the design of the practical components and their relevance to the constructive alignment (Biggs, 1996; Hoddinott, 2000) of the learning material and proficiency outcomes-skills and theory (Piccoli, Ahmad, \& Blake, 2001) in the microbiology unit.

Table 1. Design of the online and face-to-face sessions.

\begin{tabular}{|c|c|c|c|}
\hline Week & Practical & Content and Learning Focus & Learning Outcome \\
\hline 1 & \multicolumn{3}{|c|}{ Orientation to practicals/discussion of practical component requirements } \\
\hline 2,3 & Online & Theory terminology, basics & Knowledge, comprehension \\
\hline $4,5,6$ & Online & Theory \& virtual application & $\begin{array}{l}\text { Knowledge, comprehension, } \\
\text { application }\end{array}$ \\
\hline 7 & \multicolumn{3}{|c|}{ Laboratory project designed for major assessment } \\
\hline $8,9,10$ & Laboratory & Laboratory techniques, identification procedures & $\begin{array}{c}\text { Knowledge, comprehension, } \\
\text { application, analysis }\end{array}$ \\
\hline 11 & Major assessment & & $\begin{array}{l}\text { Knowledge, comprehension, } \\
\text { application, analysis, } \\
\text { synthesis, evaluation }\end{array}$ \\
\hline
\end{tabular}

\section{Method}

\subsection{Data Collection Tools}

Data collection for the study involved the use of a questionnaire (see Appendix) in order to gather baseline data regarding students' perceptions of their learning experience in a first year second semester microbiology foundation unit and how this information informs future learning and teaching design within the constraints of increasing student cohorts and physical limitations of laboratory space.

The questionnaire comprised three parts:

- Part A contained five items related to student demographic information;

- Part B contained 12 items about students' perceptions of the online and face-to-face microbiology practicals 
to which students responded using a Likert scale including a neutral response;

- Part C contained four open-ended questions related to students' learning experiences and their preferences for, and perceptions of, face-to-face practical sessions, on-line practical sessions or a combination of the two styles.

The items in Part A requested students' gender, age, course of study, and time spent and location used for studying online practicals. Part B sought students' perceptions about enjoyment, preferences, and perceptions of the quality of the learning experiences offered by each of the two practical formats. Three items in Part C sought comments from the students on their preference for one or other, or a combination of, the two practical options. The fourth item invited general comments from the students. The incorporation of these four qualitative items allowed for triangulation of the quantitative results (Perone \& Tucker, 2003).

The questionnaire was administered by an independent researcher from outside the Faculty of Health Science.

Approval for the project was obtained from the Human Research Ethics Committee (Tasmania): (Approval H12753).

\subsection{Participants}

The unit enrolment comprised 102 first year higher education students. Seventy-two of these students: 42 (58\% of participants) female and $30(42 \%)$ male-completed questionnaires. The percentages of males and females who completed the questionnaires approximated the percentages enrolled in the unit. Participants comprised 71 percent of the total unit enrolment. The students were from the Faculties of Health Science, Science Engineering and Technology, Business, and Arts.

\subsection{Data Collection}

In week 12 of Semester 1, 2012, during a face-to-face lecture session in the Microbiology \& Health unit, students were presented with an overview of the project by the independent researcher. They were extended an invitation to complete a questionnaire in week 13. Questionnaire sheets were distributed to all students. To preserve the anonymity of students, firstly they placed their questionnaires into an envelope as they left the lecture theatre and finally the independent researcher collated the student responses in a de-identified form.

\subsection{Data Analysis}

The numerical data from the questionnaire were imported into STATA (Version11 StataCorp, 1996-2010). Averages and percentages were calculated and t-tests, and in one instance a Likelihood Ratio test, were performed. Data were plotted for Figures 1-3 using GraphPad Prism version 6.00 for Windows. The text from the openended items on the questionnaire was thematically coded manually (Denzin \& Lincoln, 2011; Saldana, 2009).

\section{Results}

\subsection{Demographics}

Most students were aged between 18 and 21 years; the median and mode were 19 years and the mean was 19.5 years. Ages ranged between 18 and 28 years. Students were enrolled in Bachelor of Biomedical Science $(n=$ $15)$, Bachelor of Health Science $(n=35)$, Bachelor of Exercise Science $(n=17)$, Bachelor of Medical Imaging/Radiation $(n=3)$, Bachelor of Environmental Health $(n=1)$ and Bachelor of Science $(n=1)$ courses.

Two hours (120 $\mathrm{min}$ ) was the recommended time for completion of each online practical. Students spent from 0 - 180 minutes on each of the online sessions. For analysis, ten time blocks were established: 0 minutes, eight 15 -minute blocks ( 1 - 14, $15-29,30-44 \cdots 135-149)$, and $\geq 150$ minutes. Table 2 presents data regarding time spent and students' gender.

Table 2. Time spent on online practicals by male and female students, number (\%).

\begin{tabular}{ccccccccccc}
\hline Students-gender & \multicolumn{7}{c}{ Time } \\
\hline Male & $1(3)$ & $1(3)$ & $3(9)$ & $7(22)$ & $1(3)$ & $4(12)$ & $3(9)$ & $4(12)$ & $6(20)$ & $2(6)$ \\
Female & $1(2)$ & $0(0)$ & $1(2)$ & $7(17)$ & $1(2)$ & $8(19)$ & $3(7)$ & $8(19)$ & $8(19)$ & $4(10)$ \\
Total & $2(3)$ & $1(1)$ & $4(6)$ & $14(19)$ & $2(3)$ & $12(17)$ & $6(8)$ & $12(17)$ & $14(19)$ & $6(8)$ \\
\hline
\end{tabular}


The majority of responses clustered around spending between 1 and 2.5 hours studying each online practical. Another sizeable group of students spent 30 to 44 minutes. Time spent studying the online practical has been used to indicate completion of the material but no specific data on completion was collected.

\subsection{Preference for On-Campus or Off-Campus Study}

Students studied the online practicals either on campus, off campus, or a combination of the two. Table 3 presents locations and numbers of students.

Table 3. On-campus and off-campus study preferences for male and female students, number (\%).

\begin{tabular}{cccc}
\hline Student cohort & On campus & Location Off campus & Both \\
\hline Male n (\%) & $7(23)$ & $15(50)$ & $8(27)$ \\
Female $\mathrm{n}(\%)$ & $6(15)$ & $21(53)$ & $13(32)$ \\
\hline
\end{tabular}

At least half of both the male and the female students sampled studied the online practicals off campus. The remainder of the male students was split fairly evenly between study on campus and a combination of the two locations (Table 3). Of the remaining female students, approximately one third studied on campus whereas close to two thirds studied in a combination of the two locations. A small number of students reside on campus; however, no data were collected to differentiate this group from the total number of students who studied the online practicals using campus facilities.

\subsection{Likert Scale Questions about Preferences, Understanding and Value}

The questionnaire contained twelve items in which students selected from a five point Likert scale from "strongly agree" through to "strongly disagree" options. Students were asked about their enjoyment, preference, enhancement of understanding, and knowledge and value of the online laboratory sessions.

Figure 1 presents the results of the Likert scale item responses by all students. The strongly agree (SA) and agree (A) responses were combined and designated as "strongly agree/agree" (SA/A) for female and male students and the responses for disagree (D) and strongly disagree (SD) as "disagree/strongly disagree" (D/SD) for female and male students. Neutral responses were omitted from the tables and the data analysis.

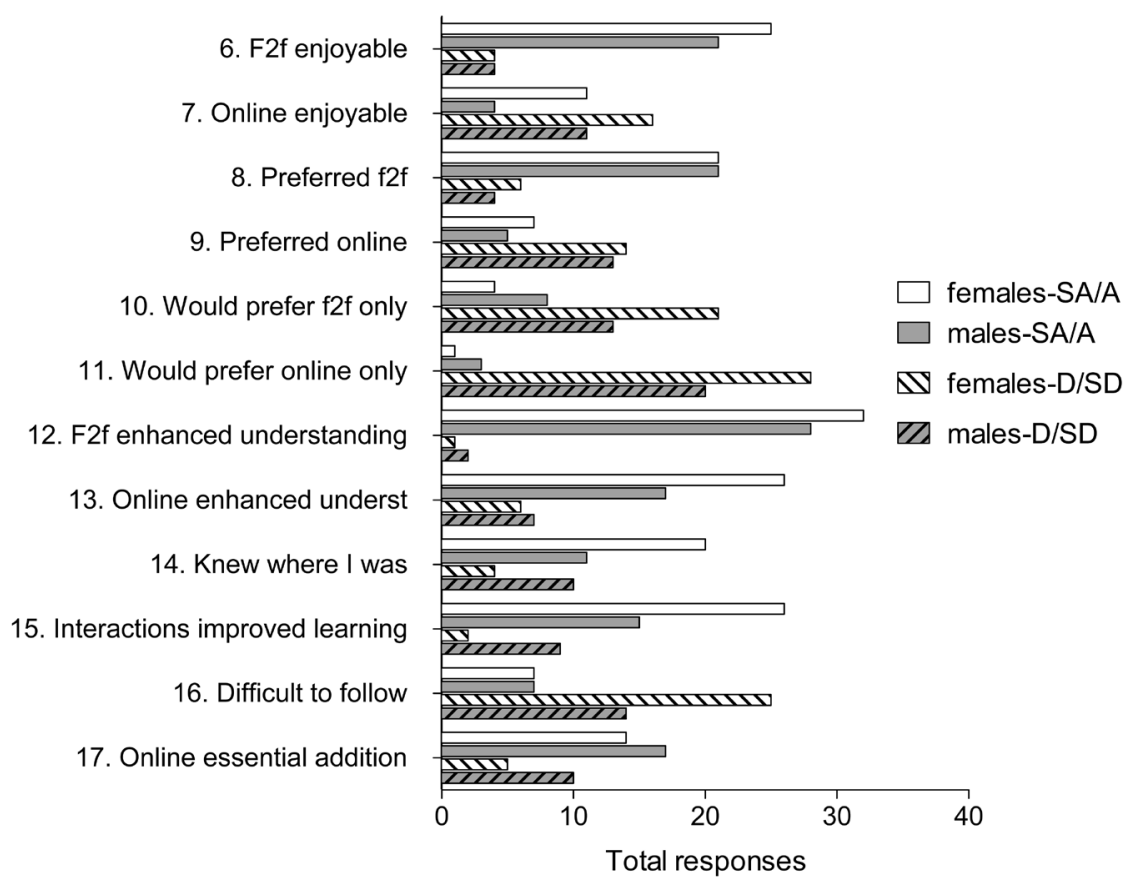

Figure 1. Likert scale items for female and male student preferences and perceptions of modes of learning. 
Students responded more favorably about their experience of face-to-face sessions than the online sessions. Nonetheless, aspects of the online sessions received positive feedback. Almost two thirds of the students either agreed or strongly agreed that they: 1) enjoyed face-to-face sessions (Item $6, n=46,64 \%$ of total student sample); 2) preferred face-to-face sessions (Item $8, n=42,58 \%$ ); 3 ) understood better as a result of face-to-face sessions (Item 12, $n=60,83 \%$ ); and, to a lesser extent; 4) had a higher level of understanding as a result of online sessions (Item 13, $n=43,60 \%$ ); and 5) that their learning improved because of the different types of interactions (e.g., animations) in the online labs (Item 15, $n=41,57 \%$ ). The combination of face-to-face and online sessions was the preferred option. Responses to the first three open-ended questions (Items 18, 19, 20), which related to students' preferences for delivery modes, showed that 47 (65\%) preferred a combined approach (Item 18), 12 (17\%) preferred face-to-face delivery only (Item 20 ) and3 (4\%) preferred online delivery only (Item 19). Ten students (14\%) indicated no preference.

More than half the students either disagreed or strongly disagreed with two items: 1) that they would prefer online sessions only (Item 11,n=48,67\%) and 2) that it was difficult to follow the material on the online labs (Item 16, $n=39,54 \%$ ). Although most students preferred face-to-face sessions, almost half of the student sample disagreed that they would prefer face-to-face sessions only (Item 10, $n=34,47 \%$ ), which is important in relation to establishing the value of online sessions as a component of a combined modes approach to teaching laboratory work. Analysis of the male students' comments to the open-ended items suggested that three issuespractical application (transfer) of learning, having direct access to the lecturer, and student accountability - may have informed their responses to Likert scale Item 10 ("I would prefer f2f lab sonly").

Students were less decisive about the enjoyable nature of online sessions (Item 7) and their preference for these sessions (Item 9). Both of these questions attracted more negative responses than positive ones. Forty-two per cent of students $(n=31)$, however, believed that online sessions were an essential addition to the laboratory sessions overall (approximately double the number who disagreed).

Figure 2 depicts the "net agreement" by gender for student preferences and perceptions of modes of learning. Net agreement was determined by calculating the difference between the totals of "agree" (A/SA) and "disagree" $(\mathrm{D} / \mathrm{SD})$.

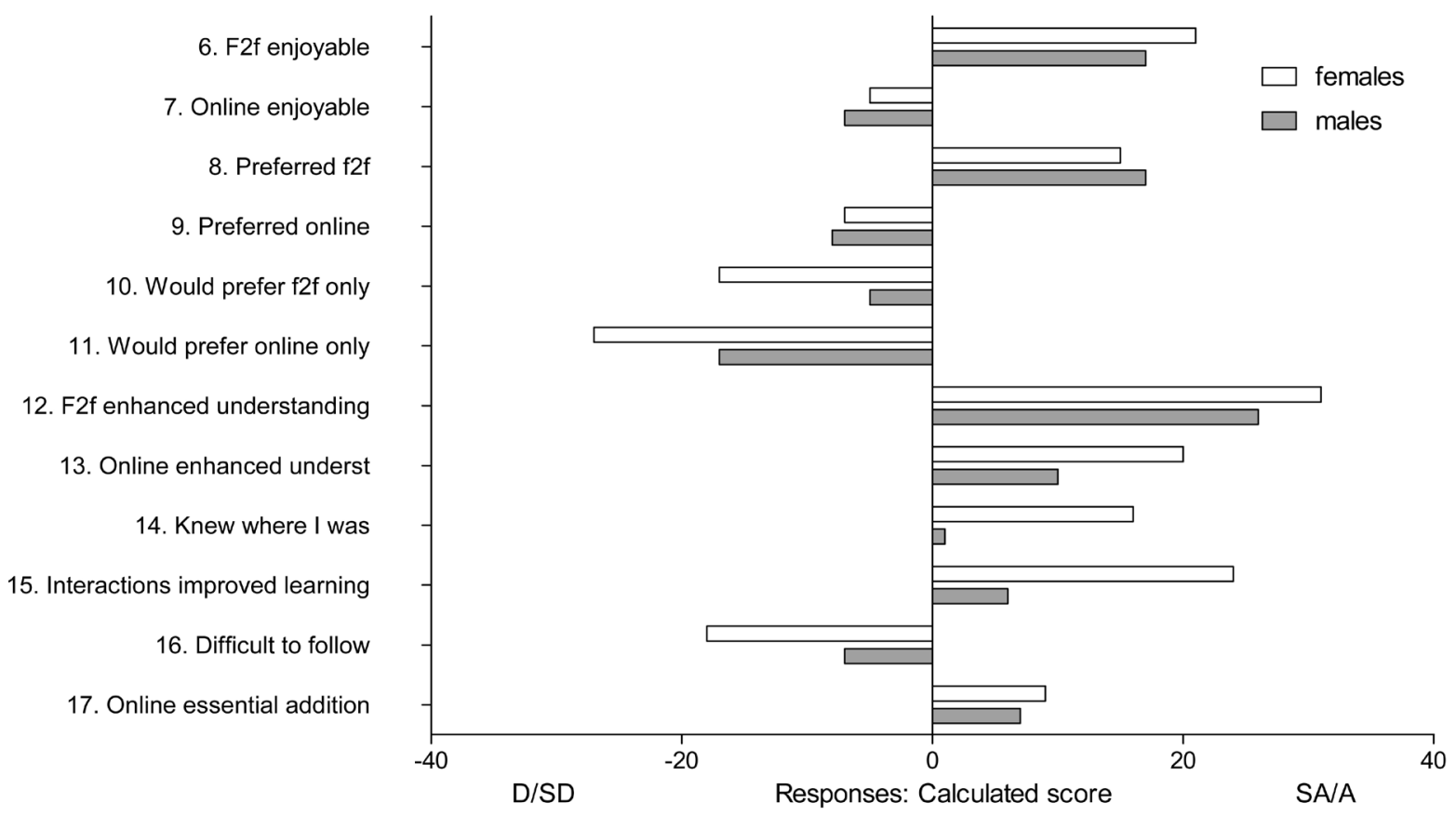

Figure 2. Net differences in agree/disagree responses by gender (total 42 females; 30 males).

Both males and females reported net agreement in either positive terms or negative terms for each item. Net agreement was positive with respect to Items $6,8,12,13,14,15$ and 17 and disagreement (negative agreement) was expressed with respect to Items $7,9,10,11$ and 16 . While there were more female responses than male res- 
ponses, males found online learning less enjoyable (Item 7) than their female counterparts and expressed more preference for face-to-face labs (Item 8). Neither result for these two items, however, is statistically significant. The mode of learning could be of particular interest for the researchers to investigate and track with samples in subsequent years.

The results for Items 14 and 15 were compared using t-tests. Furthermore, to add a qualitative dimension to the results, some student comments follow. Firstly, more females than males reported knowing "where I was and where I had come from" in the online labs (Item 14, $p=0.016$ ); and finally, more females than males found the different types of interactions improved their learning (Item 15, $p=0.042$ ).

Regarding the female students' agreement that they "knew where they were" during online sessions (Item 14) and about the helpfulness of types of online interactions used (Item 15), they referred to issues of their preparation for the face-to-face labs. Their comments included: "online labs allowed for the theory side to be addressed so the practical [face-to- face labs] were more enjoyable" and further comments focused on effective use of time, for example, "more time can be taken to gain an understanding of content" and "you get to stop on slides and look up things you are unsure of." Students who provided these and similar comments spent between 1.5 and 2 hours studying per online session.

Figure 3 illustrates the positive correlation between strength of responses and the average time spent on online tutorials. Students who spent longer on each of the online laboratory sessions typically responded more "strongly", either in agreement or in disagreement, to Items 6 to 17.

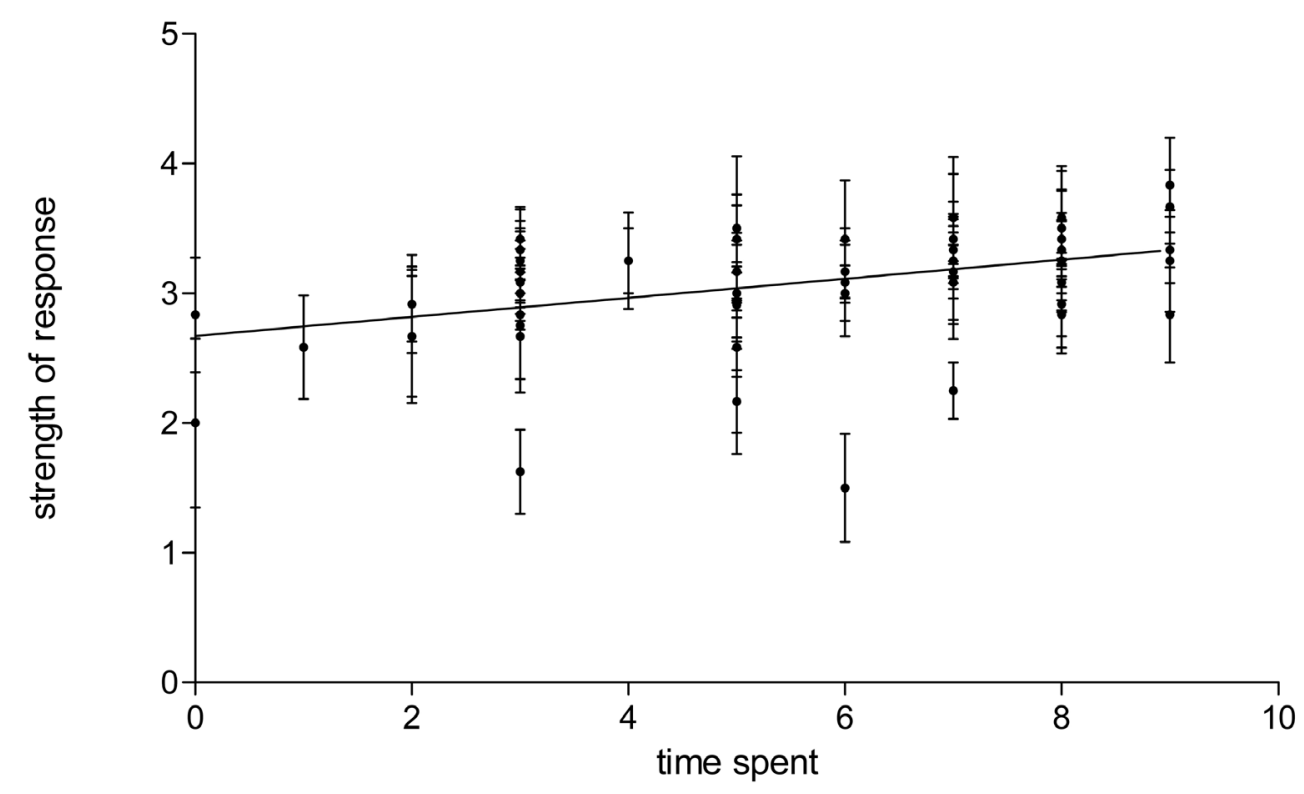

Figure 3. Correlation between average time students (male and female) spent on tutorials and the strength of their responses to the Likert scale items (6 to 17).

Transfer of learning, where students are able to recognize and make links between material in different formats, and apply skills, knowledge and attitudes from one learning situation to another is an important aspect of the learning process (Britten, New, Sharma, \& Yardley, 2005; Collins, Greeno, \& Resnick 2001; Grossman, 2005; Lobato, 2006; Macauley \& Cree, 1999). In a similar fashion, regarding practical application of learning during face-to-face labs, comments provided by students included "it makes you apply knowledge to physical applications", "hands-on experience", "achieve a greater understanding", "cements student understanding" and "provide some connection".

Preferences to have both direct and immediate access to the teacher, and to be accountable for their work, were expressed in particular by male students. Their comments identified opportunities such as: "to learn from experienced instructors", "to interact with the teachers in the labs", "to talk through problems with the lecturer" and "it is easier to learn when being directed by a teacher". The issues of immediacy and of accuracy of information were highlighted in comments by students about enabling them to "receive the [essential] content infor- 
mation", “ask questions and get [immediate] answers" and "ask questions afterwards rather than having to wait for emails".

Regarding student accountability, male students' comments about their preference for face-to-face laboratory sessions identified issues of having to attend and regularly complete laboratory work, and referred to their access of the internet off-campus.

Given the very small number of responses from each of the two genders for Items 6 to 17, it was not possible to use other tests to analyze the data to guard against relying upon the effects of using repeated t-tests. Likelihood Ratio tests were performed and the results are presented in Table 4.

Table 4. Likelihood Ratio (LR) tests-Item 17 compared with each of Items 14 \& 15 Item 17-online an essential addition to face-to-face.

\begin{tabular}{|c|c|c|c|c|c|c|}
\hline & & \multicolumn{3}{|c|}{ Item 17} & \multirow{2}{*}{ LR } & \multirow{2}{*}{$\mathrm{p}$-value } \\
\hline & & & SD \& D & A \& SA & & \\
\hline \multirow[t]{2}{*}{ Item 14} & Item 14 & SD \& D & 9 & 1 & \multirow{2}{*}{15.6250} & \multirow{2}{*}{0.0001} \\
\hline & & A \& SA & 3 & 17 & & \\
\hline \multirow[t]{2}{*}{ Item 15} & Item 15 & SD \& D & 8 & 3 & \multirow{2}{*}{15.9528} & \multirow{2}{*}{0.001} \\
\hline & & $A \& S A$ & 2 & 23 & & \\
\hline
\end{tabular}

The results of the analysis shown in Table 4 confirmed that students who considered that online learning was an essential addition to the traditional face- to-face laboratory sessions (Item 17) also believed that online learning would enhance their understanding (Item 15) and that they would not find it difficult to follow the online content (Item 14) was supported in this instance.

\section{Discussion}

Extrapolating from the data collected, students' preference for a combination of online and face-to-face sessions emerged as the preferred option. Students appreciated the opportunity of being able to work flexibly and at their own pace online; they considered that some information was better accessed and visualised online rather than in face-to-face laboratory sessions. The online sessions also served as preparation for the face-to-face laboratories. On the other hand, face-to-face sessions allowed for application of learning in a real-life setting and direct access to the lecturer. Therefore, the combined approach promoted a variety of learning experiences and catered for a range of learning styles. Two key areas which will be focused upon here are time management and gender responses to using online learning environments. These are chosen because time management is an important generic graduate/employability skill embedded in all units of study and the literature is sometimes unclear as to whether there are gender differences in approaches to online learning.

\subsection{Time Management}

In a recent study (Crawley \& Fetzner, 2013), the most common comments from students who experienced difficulty with online learning centred on keeping up with sessions, time management, self-organization skills and establishing a study routine. Although Crawley and Fetzner's study was about online lectures, as opposed to online sessions as a precursor to face-to-face laboratory sessions, these comments are not dissimilar to some of the issues that emerged in students' comments from our current study.

Students who generally spent less than one hour studying each online session were more likely to make the least enthusiastic comments regarding the value of these sessions. Those who viewed the online sessions more favourably typically spent 1.5 to 2 hours studying each online session. Whether students tend to enjoy and gain from the online sessions because of their study disposition or, alternatively, whether they can develop their capacity for online study through well-structured and increasingly successful experiences, are areas for possible study in subsequent research in this project.

\subsection{Gender Responses to Online Learning-Determinants of Engagement}

Female students reported higher levels, although not significantly higher, of understanding of the online sessions. 
They commented that they knew "where they were" and where they "had come from" and that the "different kinds of interactions improved their learning." This observation is interesting when compared to the findings of Hargittai and Shafer (2006) who noted that females tended to have a lower self-perception of their online navigation skills. This finding parallels in part, literature reviewed by Astleitner and Steinberg (2005) and findings reported by Cuadrado-García, Ruiz-Molina and Montoro-Pons (2010) regarding the influences of motivation, cognition and emotion being more influential than gender. Johnson and Gedney (2001) arrived at similar conclusions with respect to the valuable learning supports that can be offered via online learning environments. The Sunal et al. (2003) study, with respect to the value of online instruction, was not differentiated by male and female students' responses. Our findings are analogous with those of Sullivan (2001), who suggested that female students responded more favourably than male students to some advantages (resources and navigation links) of online learning environments. Sullivan's study, however, pointed to male students being more positive about working independently online, and he noted that females commented more frequently about the lack of interpersonal or face-to-face interaction in online classes. Our study did not generate data that supported Sullivan's finding (above) with respect to male students working independently. Findings from the current study suggested that males preferred face-to-face laboratory sessions in the current combined approach, although this finding was not statistically significant. As was the case in Crawley and Fetzner's 2013 study, Sullivan's focus was on the use of online classrooms only, rather than online sessions as a component of a unit in which face-to-face laboratories comprised an important part.

More males (23\%) than females (14\%) completed the online sessions on computers on campus. Reasons for this difference could include access to the Internet, access to peers, timetable, preference for on-campus study and living on campus. One male student mentioned that being able to study online had financial benefits for a student who could study from home; this student lived 200 kilometres from the university campus.

Determinants for engagement with online sessions varied with student gender. Female students in this study cited motivation, self-direction, commitment and allocation of sufficient time. Male students referred to no requirement to hand in work from online sessions; preferred learning style; and, development of independent learning styles. Results of this study pointed to female students finding the online sessions both easier to navigate and more beneficial for more their learning. Gender differences supported by Hiltz and Shea (2005) suggest that females interact more successfully with others in an online learning setting than males due to their higher communication skills and greater preference for collaborative learning approaches.

\section{Future Directions}

"Working alone" and "working in pairs" has emerged as an area for study in the next stage of the current research project. The literature indicates there is an improvement in understanding of content when students work together (Williams \& Kessler, 2002); although student gender may influence this (Cuadrado-García, Ruiz-Molina and Montoro-Pons, 2010; Hiltz \& Shea, 2005). The option of working in small groups while studying the online sessions in the university computer laboratories is to be investigated.

One female student commented that information, which was "not entirely understood", could be "looked up either on the Internet or in a book". This observation raises the issue of how students seek clarification when studying material provided by the lecturer but when not completing a laboratory session on campus in the presence of the lecturer.

Methods of validation of these sites and resources used for clarification need investigation and data could be gathered on this area in a future study.

Whether students tend to enjoy and gain from the online sessions because of their study disposition which they bring to tertiary education or, alternatively, whether they can develop their capacity for online study of practically applied knowledge through well-structured and increasingly positive learning experiences, are areas for possible study in subsequent research. Furthermore, over time, the possibility of changes in learning style preferences indicated by students, and potential reasons for these changes, could form a basis for future research.

\section{Conclusion}

Although most students preferred face-to-face sessions, students also indicated that a combination of the two methodologies was an acceptable inclusion in the unit. Face-to-face sessions only and online sessions only were the lesser-preferred options. This suggests that using online practical sessions as the precursor to the laboratory 
sessions can provide students with positive experiences as preparation for laboratory sessions. The results of this study are beginning to reveal insights into the constructive alignment process of scaffolding the online and face-to-face practical skills and learning programs across diverse and large student cohorts. The study will add to the current developing body of knowledge in this area which has typically focused on an "either-or" scenario rather than the combined approach central to this study.

\section{References}

Alonso, F., López, G., Manrique, D., \& Viñes, J. M. (2005). An Instructional Model for Web-Based E-Learning Education with a Blended Learning Process Approach. British Journal of Educational Technology, 36, 217-235. http://dx.doi.org/10.1111/j.1467-8535.2005.00454.x

Anderson, L. W., \& Krathwohl, D. R. (2001). A Taxonomy for Learning, Teaching and Assessing: A Revision of Bloom's Taxonomy of Educational Objectives. Boston, MA: Pearson.

Astleitner, H., \& Steinberg, R. (2005). Are There Gender Differences in Web-Based Learning? An Integrated Model and Related Effect Sizes. AACE Journal, 13, 47-63.

Baker, N., \& Verran, J. (2004). The Future of Microbiology Laboratory Classes-Wet, Dry or in Combination?.Nature Reviews Microbiology, 2, 338-342.

Biggs, J. (1996). Enhancing Teaching through Constructive Alignment. Higher Education, 32, 347-364. http://dx.doi.org/10.1007/bf00138871

Blewett, E. L., \& Kisamore, J. L. (2009). Evaluation of an Interactive, Case-Based Review Session in Teaching Medical Microbiology. BMC Medical Education, 9, 1-9.

Britten, S., New, P., Sharma, M., \& Yardley, D. (2005). A Case Study of Transfer of the Transfer of Mathematics Skills by University Students. International Journalof Mathematics Education in Science and Technology, 36, 1-13. http://dx.doi.org/10.1080/00207390412331271401

Collins, A., Greeno, J., \& Resnick, L. (2001). Educational Learning Theory. The International Encyclopaedia of the Social and Behavioural Sciences. New York: Elsevier Science.

Cook, M. P. (2006). Visual Representations in Science Education: The Influence of Prior Knowledge and Cognitive Load Theory on Instructional Design Principles. Science Education, 90, 1073-1091. http://dx.doi.org/10.1002/sce.20164

Crawley, A., \& Fetzner, M. (2013). Providing Innovative Service to Students inside and outside of the Online Classroom: A Student Perspective. Online Learning: Official Journal of the Online Learning Consortium, 17, 7-12.

Cuadrado-García, M., Ruiz-Molina, M. E., \& Montoro-Pons, J. D. (2010). Are There GENDER Differences in E-Learning Use and Assessment? Evidence from an Interuniversity Online Project in Europe. Procedia-Social and Behavioral Sciences, 2, 367-371. http://dx.doi.org/10.1016/j.sbspro.2010.03.027

Dee, F. R., Lehman, J. M., Consoer, D., Leaven, T., \& Cohen, M. B. (2003). Implementation of Virtual Microscope Slides in the Annual Pathobiology of Cancer Workshop Laboratory. Human Biology, 34, 430-436.

Denzin, N. K., \& Lincoln, Y. S. (2011). The SAGE Handbook of Qualitative Research. Thousand Oaks, CA: Sage.

Evans, C., Gibbons, N. J., Sha, K., \& Griffin, D. K. (2004). Virtual Learning in the Biological Sciences: Pitfalls of Simply "Putting Notes on the Web". Computers \& Education, 43, 49-61. http://dx.doi.org/10.1016/j.compedu.2003.12.004

Finkelstein, N. D., Adams, W. K., Keller, C. J., Kohl, P. B., Perkins, K. K., Podolefsky, N. S., \& LeMaster, R. (2005). When Learning about the Real World Is Better Done Virtually: A Study of Substituting Computer Simulations for Laboratory Equipment. Physical Review Special Topics: Physics Education Research, 1, 1-8.

http://dx.doi.org/10.1103/PhysRevSTPER.1.010103

Gilman, S. L. (2006). Do Online Labs Work? An Assessment of an Online Lab on Celldivision. American Biology Teacher, $68,131-134$.

Grossman, R. (2005). Discovering Hidden Transformations: Making Science and Other Courses More Learnable. College Teaching, 53, 33-40. http://dx.doi.org/10.3200/CTCH.53.1.33-40

Hargittai, E., \& Shafer, S. (2006). Differences in Actual and Perceived Online Skills: The Role of Gender. Social Science Quarterly, 87, 432-448. http://dx.doi.org/10.1111/j.1540-6237.2006.00389.x

Hiltz, S. R., \& Shea, P. (2005). The Student in the Online Classroom. Learning Together Online. In S. R. Hiltz, \& R. Goldman (Eds.), Research on Asynchronous Learning Networks (pp. 145-168). Mahwah, NJ: Lawrence Erlbaum Associates.

Hoddinott, J. (2000). Biggs' Constructive Alignment: Evaluation of a Pedagogical Model Applied to a Web Course. In Proceedings of ED-MEDIA 2000, World Conference on Educational Multimedia, Hypermedia \& Telecommunications, Montreal (pp. 1631-1632). 
Johnson, T. E., \& Gedney, C. (2001). Learning Support Assessment Study of a Computer Simulation for the Development of Microbial Identification Strategies. Journal of Microbiology \& Biology Education, 2, 18-24. http://dx.doi.org/10.1128/154288101X14285805863424

Lobato, J. (2006). Transfer Strand: Alternative Perspectives on the Transfer of Learning: History, Issues, and Challenges for Future Research. The Journal of the Learning Sciences, 15, 431-449. http://dx.doi.org/10.1207/s15327809j1s1504_1

Macauley, C., \& Cree, V. E. (1999). Transfer of Learning: Concept and Process. Social Work Education: The International Journal, 18, 183-194. http://dx.doi.org/10.1080/02615479911220181

Maldarelli, G. A., Hartmann, E. M., Cummings, P. J., Horner, R.D., Obom, K.M., Shingles, R., \& Pearlman, R. S. (2009). Virtual Lab Demonstrations Improve Students' Mastery of Basic Biology Laboratory Techniques. Journal of Microbiology \& Biology Education, 10, 51-57. http://dx.doi.org/10.1128/jmbe.v10.99

Papo, W. (2001). Integration of Educational Media in Higher Education Large Classes. Educational Media International, 38 , 95-99. http://dx.doi.org/10.1080/09523980110041908

Perone, J. S., \& Tucker, L. (2003). An Exploration of Triangulation of Methodologies: Quantitative and Qualitative Methodology Fusion in an Investigation of Perceptions of Transit Safety. Report No. NCTR-416-08.1-08.2. http://www.dot.state.fl.us/research-center/Completed_Proj/Summary_PTO/FDOT_BC137_22_rpt.pdf

Phillips, V., \& Bond, C. (2004). Undergraduates' Experiences of Critical Thinking. Higher Education Research \& Development, 23, 277-294. http://dx.doi.org/10.1080/0729436042000235409

Piccoli, G., Ahmad, R., \& Ives, B. (2001). Web-Based Virtual Learning Environments: A Research Framework and a Preliminary Assessment of Effectiveness in Basic IT Skills Training. MIS Quarterly, 25, 401-426. http://dx.doi.org/10.2307/3250989

Rajagopal, I., \& Bojin, N. (2003). A Gendered World: Students and Instructional Technologies. First Monday, 8. http://dx.doi.org/10.5210/fm.v8i1.1023

Saldana, J. (2009). The Coding Manual for Qualitative Researchers. Los Angeles, CA: Sage.

Sancho, P., Corral, R., Rivas, T., Gonzalez, M. J., Chordi, A., \& Tejedor, C. (2006). A Blended Learning Experience for Teaching Microbiology. American Journal of Pharmaceutical Education, 70, 120.

Saunders, G., \& Klemming, F. (2003). Integrating Technology into a Traditional Learning Environment Reasons for and Risks of Success. Active Learning in Higher Education, 4, 74-86.

Shibley, I., Amaral, K. E., Shank, J. D., \& Shibley, L. R. (2011). Designing a Blended Course: Using ADDIE to Guide Instructional Design. Journal of College Science Teaching, 40, 80-85.

Stuckey-Mickell, T. A., \& Stuckey-Danner, B. D. (2007). Virtual Labs in the Online Biology Course: Student Perceptions of Effectiveness and Usability. Journal of Online Learning and Teaching, 3, 105-111.

Sunal, W. S., Sunal, C. S., Odell, M. R., \& Sundberg, C. A. (2003). Research-Supported Best Practices for Developing Online Learning. The Journal of Interactive Online Learning, 2, 1-40.

Sullivan, P. (2001). Gender Differences and the Online Classroom: Male and Female College Students Evaluate Their Experiences. Community College Journal of Research \&Practice, 25, 805-818.

Swan, K. (2001). Virtual Interaction: Design Factors Affecting Student Satisfaction and Perceived Learning in Asynchronous Online Courses. Distance Education, 22, 306-331. http://dx.doi.org/10.1080/0158791010220208

Wahlgren, C. F., Edelbring, S., Fors, U., Hindbeck, H., \& Stahle, M. (2006). Evaluation of an Interactive Case Simulation System in Dermatology and Venereology for Medical Students. BMC Medical Education, 6, 40. http://dx.doi.org/10.1186/1472-6920-6-40

Williams, L., \& Kessler, R. (2002). Pair Programming Illuminated. Boston, MA: Addison-Wesley Longman. 


\section{Appendix}

\section{Questionnaire evaluation instrument forCXA176}

Please indicate your choice for EACH of the questions below by marking $(\sqrt{ })$ the box that best represents you or writing the answer as appropriate.

Part A: Please tell us some information about yourself.

1. What is your gender? Male $\square \quad$ Female $\square$

2. Please write your age in years.

3. What degree/course are you studying this unitin? Bachelor of Biomed Science

Bachelor of

Health Science Bachelor of

HlthSc (Envir.Hlth) Bachelor of

Exercise Science

Associate Degree

Other

4. What amount of time did you spend on each online practical?

5. Where did you work on the online practicals? Oncampus

Offcampus Both

Part B: Now we would like to ask you some questions about your perceptions of the online and face-to-face (f2f) microbiologypracticals.

6. The f2f labs were enjoyable

7. The online labs were enjoyable

8. I preferred the f2flabs

9. I preferred the onlinelabs

10. I would prefer f2f labs only

11. I would prefer online labs only

12. $\mathrm{f} 2 \mathrm{f}$ labs enhanced my understanding of the course

13. Online labs enhanced my understanding of the course

14. I felt that I always knew where I was and where I had come from in the subject material in the onlinelabs

15. The different types of interaction (animationsetc.) in the online labs improved my learning

16. I found it difficult to follow the flow and meaning of the subject material in the onlinelabs

17. I consider the online labs to be an essential addition to traditional f2flabs

Part C: Please provide some comments on your learning experiences with the two different methods of delivering the practical sessions. The following headings are suggested for comments.

18. A combination of online and face to face sessions would be the best option because...

19. Online sessions only would be the best option because...

20. Face-to-face sessions only would be the best option because...

21. Other comments:

Thank you for your assistance. 


\section{Submit or recommend next manuscript to SCIRP and we will provide best service for you:}

Accepting pre-submission inquiries through Email, Facebook, LinkedIn, Twitter, etc.

A wide selection of journals (inclusive of 9 subjects, more than 200 journals)

Providing 24-hour high-quality service

User-friendly online submission system

Fair and swift peer-review system

Efficient typesetting and proofreading procedure

Display of the result of downloads and visits, as well as the number of cited articles

Maximum dissemination of your research work

Submit your manuscript at: http://papersubmission.scirp.org/ 